\title{
A Double Trisomic in Barley (Hordeum vulgare L.)
}

\author{
Ganesh Prasad, D. K. Tripathi \\ Department of Agricultural Botany, S.D.J. Post Graduate College, \\ Chandesar, Azamgarh 276128, U.P., India \\ and
}

S. N. Mathur

Department of Botany, Gorakhpur University, Gorakhpur, U.P., India

Accepted June 12, 1984

Double trisomics $(2 x+1+1)$ have been reported to occur in the progeny of triploids and hypo-triploids (Tsuchiya 1952, 1960, Burnham 1962, Gill et al. 1970). There is no report of occurrence of such trisomics in mutagen treated materials. This paper describes the cyto-morphological aspects of a double trisomic plant isolated from the progeny of diethyl sulphate (DES) treated barley.

\section{Materials and methods}

In $M_{2}$ generation of the seeds of 6-rowed barley cultivar DL $36(2 x=14)$ treated with 0.3 per cent solution of DES, several partially sterile plants were obtained. Sporocytes were colleted in $3: 1$ alcohol-acetic acid solution and preserved in 70 per cent ethanol. Slides were prepared using 2 per cent aceto-propiono-carmine. One of the partially sterile plants was identified as a double trisomic. Data were recorded on various cytomorphological features.

\section{Results}

\section{Morphology and fertility}

The double trisomic plant was dwarf and its height was approximately half (54.7 per cent) of the height of diploid (Table 1). It was less vigorous and weak. Upper leaves were wrinkled with rolled margins. Leaf index was 15.8. It produced three tillers and short spikes. Pollen and ovule fertility were 27.0 and 2.5 per cent, respectively. A total of 3 seeds were obtained from 120 spikelets. Two of the seeds germinated and produced diploid plants.

\section{Cytology}

Meiotic study revealed the presence of 2 extra chromosomes $(2 x+1+1=16)$ at MI. There were three types of chromosome configurations observed at MI: $2^{\text {III }}+$ $5^{\mathrm{II}}$ (Figs. 1a, b, c, e), $1^{\mathrm{III}}+1^{\mathrm{I}}+6^{\mathrm{II}}$ (Fig. 1d, e), and $2^{\mathrm{I}}+7^{\mathrm{II}}$. Frequency of each type of configuration is presented in Table 2. The most frequent configuration was $1^{\text {III }}+1^{\mathrm{I}}+6^{\text {II }}(39.4$ per cent). Trivalents were V-shaped (Figs. 1a, b, c, d), J-shaped 
(Fig. 1b), rod shaped (Fig. 1e), frying-pan shaped (Fig. 1c) and Y-shaped. Data presented in Table 3 indicated that V-shape was the most frequent ( 51.3 per cent), followed by rod shape configuration ( 35.8 per cent). The Y-shape was the least frequent type (1.6 per cent).

At AI, there were observed four types of chromosome segregations namely, 8-8, 9-7, 8-1-7 and 7-2-7 (Table 4). The most frequent segregation was 9-7 which occurred in 62.5 per cent of AI cells. The least frequent segregation was 8-8 (2.5 per cent).

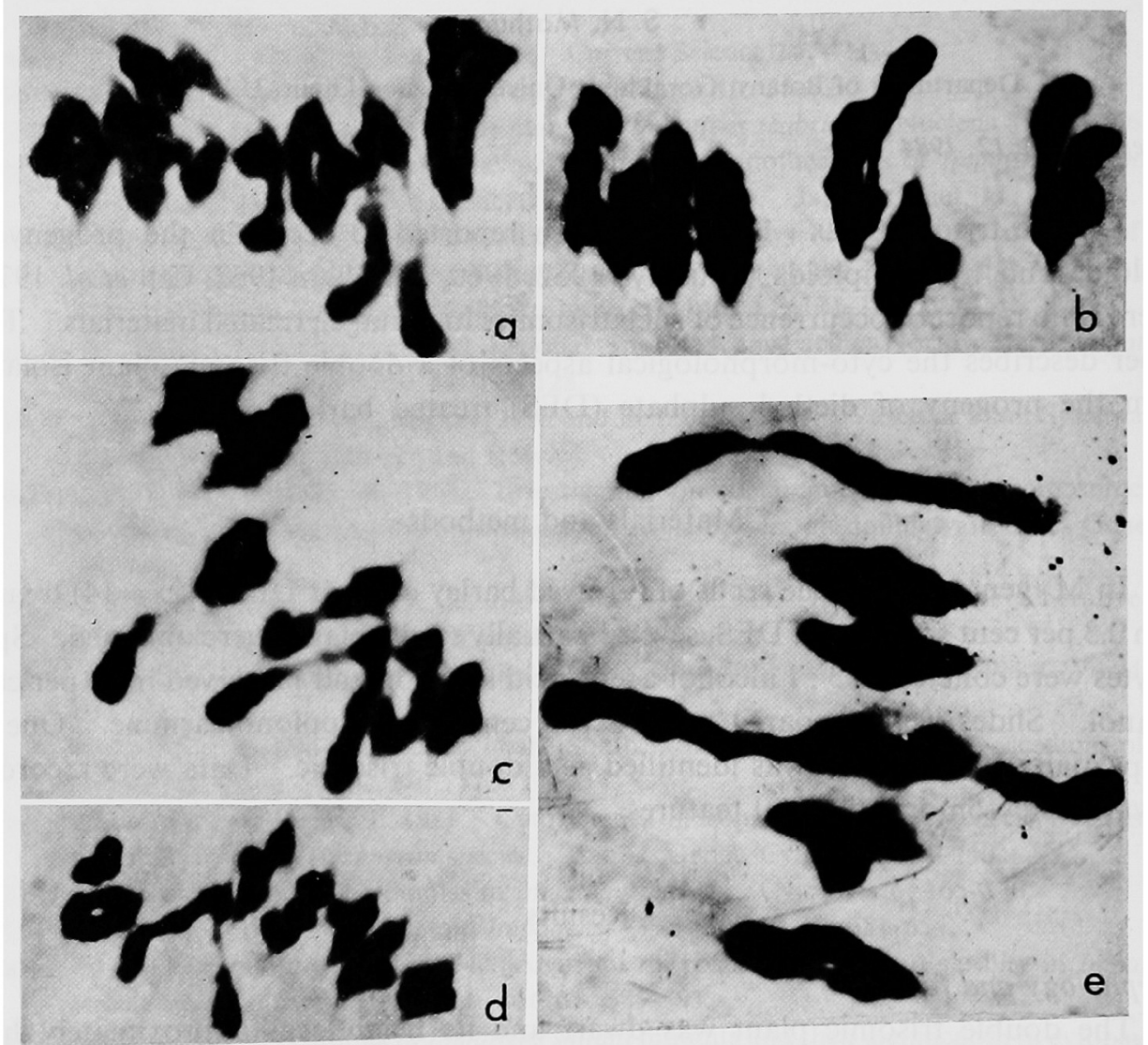

Figs. 1a-1e. 1a, $2^{\mathrm{III}}+5^{\mathrm{II}}$ (V-shape trivalents). $1 \mathrm{~b}, 2^{\mathrm{III}}+5^{\mathrm{II}}$ (V- and $\mathrm{J}$-shape trivalents). 1c, $2^{\mathrm{III}}+5^{\mathrm{II}}$ (V-and frying-pan shape trivalents). $1 \mathrm{~d}, 1^{\mathrm{III}}+1^{\mathrm{I}}+6^{\mathrm{II}}$ (V-shape trivalent). $1 \mathrm{e}, 2^{\mathrm{III}}+5^{\mathrm{II}}$ (Rod-shape trivalents).

\section{Discussion}

Meiotic configurations enable the identification of the kind of trisomics (Tsuchiya 1952, 1960, Burnham 1962). The chromosome configuration ' $2^{\mathrm{III}}+5^{\mathrm{II}}$ at MI clearly indicated that the plant was double trisomic.

Occurrence of double trisomics is not infrequent. They may originate from similar sources as for primary simple trisomics, such as, triploids (Tasuchiya 1954, 1960, 1964, 1967, Gill et al. 1970), hypo-triploids (Tsuchiya 1952) and asynaptic 
and desynaptic mutants (Gottschalk and Milutinovic 1973, Palmer and Heer 1976). In barley, Tsuchiya (1952) obtained 2 double trisomic plants out of 14 plants in the progeny of a hypo-triploid. The same author (Tsuchiya 1960) reported 19.8 per cent double trisomics and 44.8 per cent primary trisomics in the progeny of tri-

Table 1. Data on certain morphological characters and fertility in barley cultivar DL 36 and the double trisomic plant

\begin{tabular}{lcccccc}
\hline \multirow{2}{*}{ Plant } & Height & $\begin{array}{c}\text { Length of } \\
\text { spike }\end{array}$ & Tillers & Leaf & \multicolumn{2}{c}{ Fertility $(\%)$} \\
\cline { 6 - 8 } & $(\mathrm{cm})$ & $(\mathrm{cm})$ & & & Pollen & Ovule \\
\hline DL 36 & 96.0 & 8.1 & 7 & 13.7 & 98.0 & 100.0 \\
Double trisomic & 52.5 & 5.0 & 3 & 15.8 & 27.0 & 2.5 \\
\hline
\end{tabular}

Table 2. MI configurations and their frequencies in double trisomic plant

\begin{tabular}{lcc}
\hline \hline & \multicolumn{2}{c}{ Frequency } \\
\cline { 2 - 4 } MI configuration & Number & Per cent \\
\hline $1^{\text {III }}+1^{\text {I }}+6^{\text {II }}$ & 67 & 39.4 \\
$2^{\text {III }}+5^{\text {II }}$ & 64 & 37.7 \\
$2^{\text {I }}+7^{\text {II }}$ & 39 & 22.9 \\
\hline Total & 170 & 100.0 \\
\hline
\end{tabular}

Table 3. Types and frequencies of trivalents at MI in double trisomic plant

\begin{tabular}{lcc}
\hline \multirow{2}{*}{ Type of trivalent } & \multicolumn{2}{c}{ Frequency } \\
\cline { 2 - 3 } & Number & Per cent \\
\hline V-shape & 96 & 51.3 \\
Rod-shape & 67 & 35.8 \\
J-shape & 10 & 5.4 \\
Frying-pan shape & 11 & 5.9 \\
Y-shape & 3 & 1.6 \\
\hline Total & 187 & 100.0 \\
\hline
\end{tabular}

Table 4. Frequencies of different types of chromosome segregations in the double trisomic plant

\begin{tabular}{lcc}
\hline \hline & \multicolumn{2}{c}{ Frequency } \\
\cline { 2 - 3 } AI Segregation & Number & Per cent \\
$8-8$ & 1 & 2.5 \\
$9-7$ & 25 & 62.5 \\
$8-1-7$ & 4 & 10.0 \\
$7-2-7$ & 10 & 25.0 \\
\hline Total & 40 & 100.0 \\
\hline
\end{tabular}

ploid barley. Gill et al. (1970) obtained 1.3 per cent double trisomics and 42.2 per cent primary trisomics in the progeny of triploid pearl millet. Double trisomic originates when a gamete containing $x+1+1$ chromosomes is fertilized by a normal gamete. In general, male gametes with extra chromosome (s) are non-functional 
but female gametes are functional to some extent (Burnham 1962, Nilan 1964). In the present study some of the DES-treated plants showed unequal separations such as 8-6 and 9-5 in the PMC's although with a low frequency. It is probable that some functional egg with $\mathrm{x}+1+1$ chromosomes was formed and fertilized by a normal gamete resulting in the production of a double trisomic.

Triosomics are weaker and shorter as compared to diploids. Trisomics for different chromosomes may be identified by the morphological characters because each chromosome has separate effect. In barley, Tsuchiya $(1960,1964,1967)$ established trisomic series in wild and cultivated barley and classified the trisomics into seven types. However, the double trisomic reported here could not be grouped in any of the seven trisomics types because it had effects of two different chromosomes.

\section{Summary}

A double trisomic plant $(2 x+1+1=16)$ was obtained in the progeny of diethyl sulphate ( 0.3 per cent) treated barley. It was weak and dwarf and produced few tillers with short spikes. Pollen and ovule fertility were 27.0 and 2.5 per cent, respectively. MI configurations were $1^{\mathrm{III}}+1^{1}+6^{\mathrm{III}}, 2^{\mathrm{III}}+5^{\mathrm{II}}$ and $2^{\mathrm{I}}+7^{\mathrm{II}}$, the former being the most frequent. $\mathrm{V}$ - and rod-shaped trivalents were more prominent. Unequal separations and lagging of chromosomes were observed at AI.

\section{Acknowledgement}

Authors are thankful to the Head, Department of Genetics and Plant Breeding, Banaras Hindu University for providing the photomicrographic facility.

\section{References}

Burnham, C. R. 1962. Discussions in Cytogenetics. Burgess Publ. Co., Minneapolis, U.S.A. Gill, B.S., Virmani, S.S. and Minocha, J. L. 1970. Primary simple trisomics in pearl millet. Can. J. Genet. Cytol. 12: 474-483.

Gottschalk, W. and Milutinovic, M. 1973. Trisomics from desynaptic mutants. The Nucleus 16: $1-10$.

Nilan, R. A. 1964. The Cytology and Genetics of Barley, 1951-1962. Monographic Suppl. No. 3, Res. Studies, Washington State Univ. pp. 278.

Palmer, R. G. and Heer, H. 1976. Aneuploids from a desynaptic mutant in soybeans (Glycine $\max ($ L.) Merr.). Cytologia 41 : 417-427.

Tsuchiya, T. 1952. Cytogenetics of a hypo-triploid barley and its progeny. Mem. Beppu Women's Univ. 2: 19-42.

- 1954. Trisomics in barley. Jap. J. Genet. $29: 179$.

- 1960. Cytogenetic studies of trisomics in barley. Jap. J. Bot. 17: 177-213.

- 1964. Chromosome aberrations and their use in genetics and breeding in barley-trisomics and aneuploids. Proc. 1st Int. Barley Genet. Symp. Wageningen, 1963. Barley Genet. 1: $116-150$.

- 1967. The establishment of a trisomic series in a two-rowed cultivated variety of barley. Can. J. Genet. Cytol. 9: 667-682. 